\title{
The LLNL Flash X-Ray Induction Linear Accelerator (FXR)
}

\author{
L.G. Multhauf
}

This article was submitted to The $25^{\text {th }}$ Conference on High Speed Photography and Photonics, Beaune, France, September 12 October 4, 2002

\section{September 19, 2002}

U.S. Department of Energy

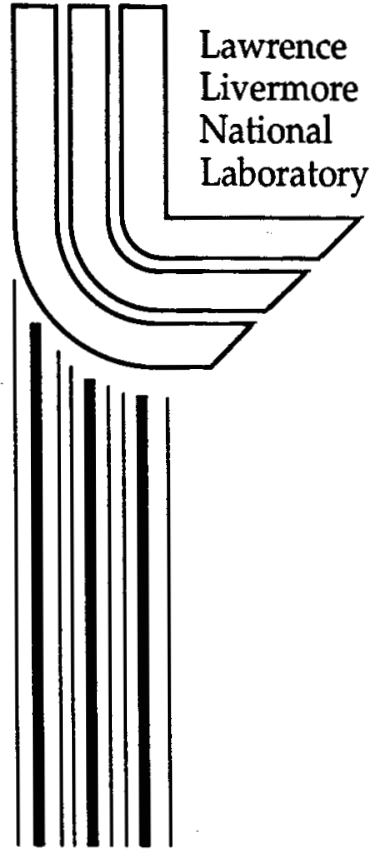




\section{DISCLAIMER}

This document was prepared as an account of work sponsored by an agency of the United States Government. Neither the United States Government nor the University of California nor any of their employees, makes any warranty, express or implied, or assumes any legal liability or responsibility for the accuracy, completeness, or usefulness of any information, apparatus, product, or process disclosed, or represents that its use would not infringe privately owned rights. Reference herein to any specific commercial product, process, or service by trade name, trademark, manufacturer, or otherwise, does not necessarily constitute or imply its endorsement, recommendation, or favoring by the United States Government or the University of California. The views and opinions of authors expressed herein do not necessarily state or reflect those of the United States Government or the University of California, and shall not be used for advertising or product endorsement purposes.

This is a preprint of a paper intended for publication in a journal or proceedings. Since changes may be made before publication, this preprint is made available with the understanding that it will not be cited or reproduced without the permission of the author.

This work was performed under the auspices of the United States Department of Energy by the University of California, Lawrence Livermore National Laboratory under contract No. W-7405-Eng-48.

This report has been reproduced directly from the best available copy.

Available electronically at http://www.doc.gov/bridge

Available for a processing fee to U.S. Department of Energy

And its contractors in paper from

U.S. Department of Energy

Office of Scientific and Technical Information

P.O. Box 62

Oak Ridge, TN 37831-0062

Telephone: (865) 576-8401

Facsimile: (865) 576-5728

E-mail: reports@adonis.osti.gov

Available for the sale to the public from

U.S. Department of Commerce

National Technical Information Service

5285 Port Royal Road

Springfield, VA 22161

Telephone: (800) 553-6847

Facsimile: (703) 605-6900

E-mail: orders@ntis.fedworld.gov

Online ordering: http://www.ntis.gov/ordering.htm

OR

Lawrence Livermore National Laboratory

Technical Information Department's Digital Library

http://www.llnl.gov/tid/Library.html 


\title{
The LLNL Flash X-ray Induction Linear Accelerator (FXR)
}

\author{
Lloyd G. Multhauf \\ Lawrence Livermore Laboratory \\ Livermore, CA USA
}

\begin{abstract}
The FXR is an induction linear accelerator used for high-speed radiography at the Lawrence Livermore National Laboratory's Experimental Test Site. It was designed specifically for the radiography of very thick explosive objects. Since its completion in 1982, it has been very actively used for a large variety of explosives tests, and has been periodically upgraded to achieve higher performance. Upgrades have addressed machine reliability, radiographic sensitivity and resolution, two-frame imaging by double pulsing improvements that are described in detail in the paper. At the same time, the facility in which it was installed has also been extensively upgraded, first by adding space for optical and interferometric diagnostics, and more recently by adding a containment chamber to prevent the environmental dispersal of hazardous and radioactive materials. The containment addition also further expands space for new non-radiographic diagnostics. The new Contained Firing Facility is still in the process of activation. At the same time, FXR is continuing to undergo modifications aimed primarily at further increasing radiographic resolution and sensitivity, and at improving double-pulsed performance.
\end{abstract}

Keywords: FXR, CFF, LIA, Contained Firing Facility, Linear Induction Accelerator, Gamma-ray Camera

\section{INTRODUCTION}

FXR $^{1}$ was the first accelerator in the US to be optimized for the radiography of thick explosive objects ( $\left.>100 \mathrm{gm} / \mathrm{cm}^{2}\right)$. It was also the first radiographic machine based on linear-induction accelerator technology, which was developed at the Lawrence Livermore National Laboratory in the magnetic fusion program. FXR was completed in 1982, producing 300 Rad at $1-\mathrm{m}$ from a $65-\mathrm{ns}, 2.2 \mathrm{kA}$ electron pulse accelerated to $16 \mathrm{MeV}$. The short pulse width was chosen to produce blur-free images of material moving at several $\mathrm{mm} / \mathrm{s}$, velocities characteristic of explosive experiments. A spot size of about 3.5-mm MTF was commonly achieved. Subsequently, both FXR, and the facility have seen major upgrades, the most recent being the construction of the Contained Firing Facility and the modification of FXR to achieve double pulsing. Further improvements are contemplated.

\section{FXR}

FXR as constructed was 42-meters long (see Figure 1), and consisted of a six-induction-cell injector followed by 48 accelerator cells (each imparting an energy of between 300 and $350 \mathrm{keV}$ to the beam), a focusing magnet, and a 1-mmthick tantalum target for producing Bremsstralung x-rays. Images of exploding test objects were produced by recording the absorption pattern across an object onto $\mathrm{x}$-ray film located in a blast-protected cassette behind the explosive device. 


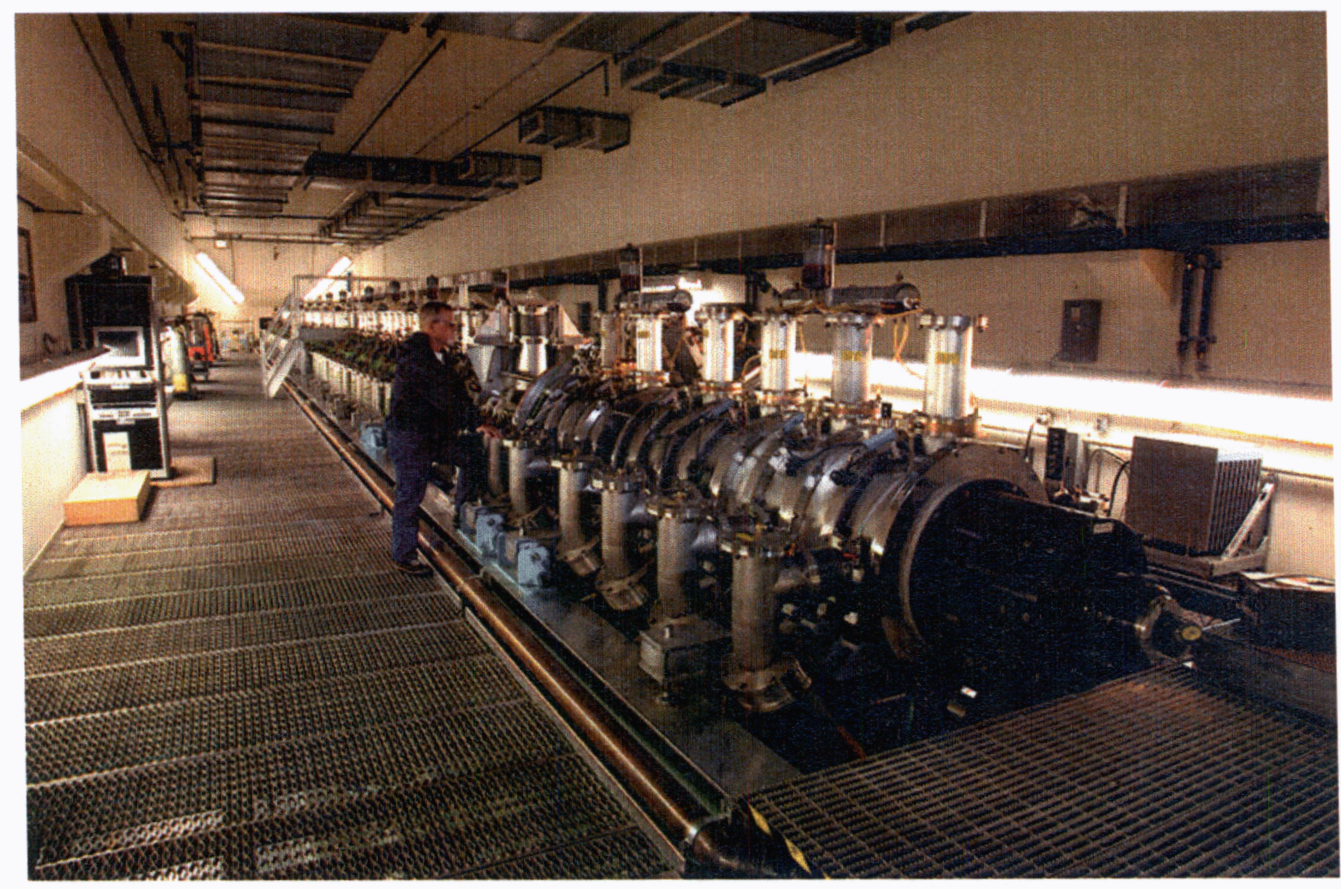

Figure 1. The FXR accelerator as viewed from the injector

In the decade following the commissioning of FXR, several modifications were made to improve radiographic performance. The first modification was the installation of magnetic triggering to replace spark gap switches, substantially improving the reliability of the machine. As a consequence, in the years since it was commissioned, there has never been a failure to obtain radiographic data on an explosive experiment. The next major improvement was the development of the Bismuth Germanate ( BGO ) gamma-ray camera to replace film. The LLNL gamma-ray camera uses 4-cm-long, segmented $(0.6 \mathrm{~mm} \times 0.6 \mathrm{~mm})$ crystals of BGO (Figure 2), a high density, high Z optical material for efficient absorption of high-energy ( $\sim-\mathrm{MeV}) \mathrm{x}$-rays, thereby increasing sensitivity over film by nearly two orders of magnitude, an improvement brought about by the high quantum efficiency of BGO and the use of an intensifier between the crystals and the optical film on which the image was recorded.

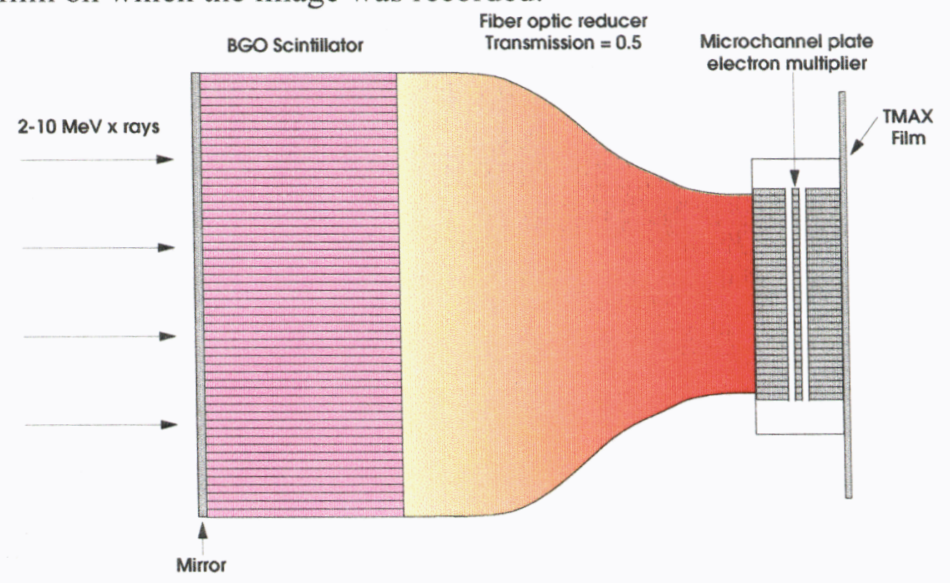

Figure 2: BGO Gamma-ray camera

The increased sensitivity enabled very thick objects to be radiographed, and was also used to produce higher image resolution (1.6 mm MTF) by introducing a sub-mm collimator just downstream of the x-ray converter target. (Figure 3) 


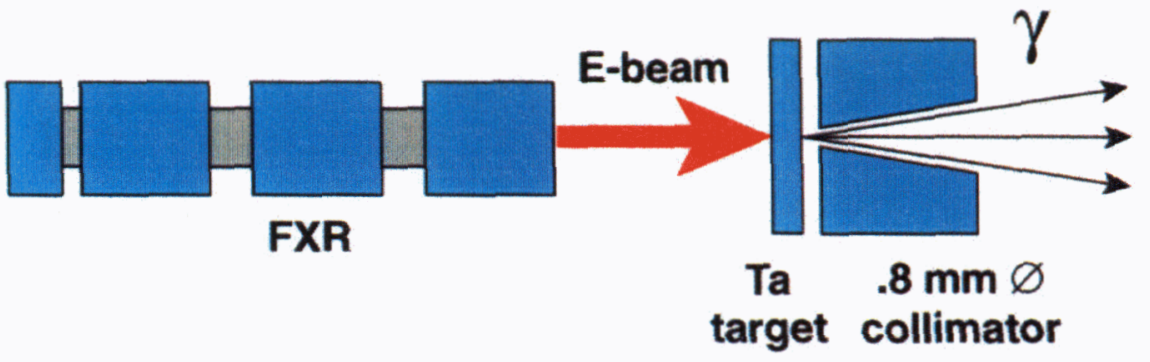

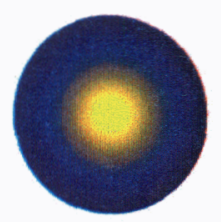

Device

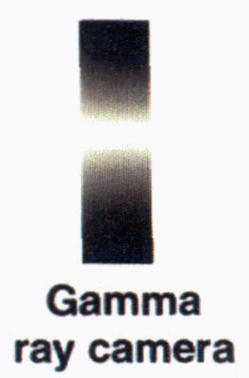

Figure 3: Schematic of a radiographic imaging experiment

\section{BUNKER 801}

FXR was installed at Bunker 801, an existing explosive test facility. At the same time that FXR was being installed, the facility was being extensively modified to support the simultaneous use of a full array of diagnostics on the single experiment. This was made possible by the addition of blast-hardened space for interferometric and optical and electrical recording equipment, creating the first true multidiagnostic explosive facility (Figure 4). With the creativity of participants exhausted in the technology, the names of the new radiographic machine and facility remained a nondescriptive FXR and Bunker 801 , respectively.

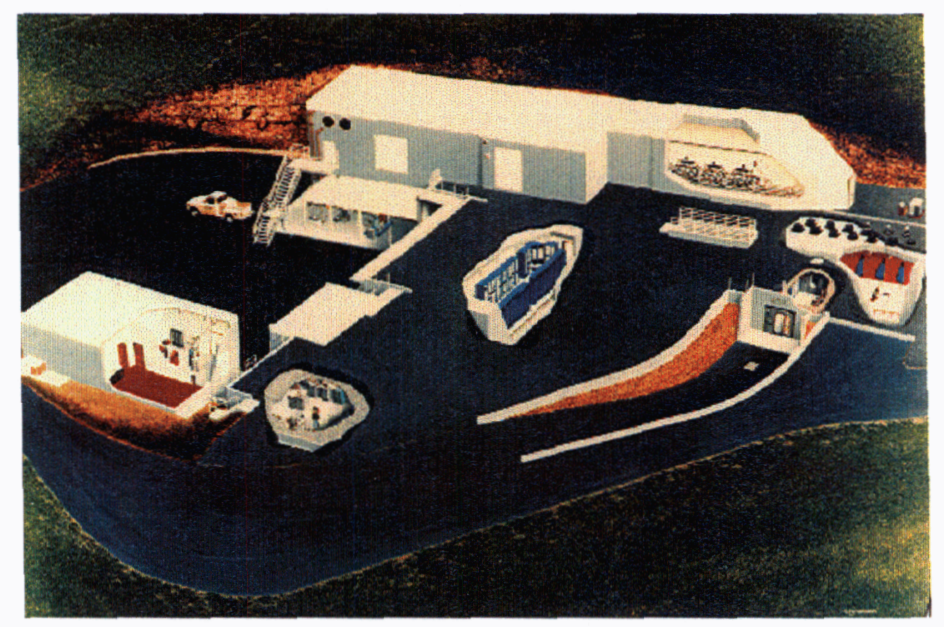

Figure 4. Bunker 801 with FXR and multidiagnostic capability

Bunker 801 is located at the Lawrence Livermore National Laboratory Site 300 Experimental Test Site, which is in the Diablo Range of California 15 miles east of the Laboratory main site. Explosives experiments at Bunker 801 have been conducted in the open air since 1955 when the site was acquired. While the Laboratory has always ensured compliance with all environmental regulations, the nearby community of Tracy has grown rapidly, and land adjacent to the Site is destined for housing. In addition, environmental regulations have been tightened over the years, and concern for the dispersing of toxic metals and radioactive materials has grown. Two materials of particular concern have been depleted uranium and beryllium. Changes in environmental regulations reflect both real hazards and public perceptions of them, and have never, therefore, been easy to forecast. But residential housing so near the Site is likely to heighten any latent concerns. By 1990 it appeared prudent to begin planning for a capability to contain the debris from some experiments, including those with hazardous material reduced to a readily dispersed, easily inhalable aerosolized form. A concurrent need existed for expanded space for new diagnostics developed to provide a more detailed understanding of explosive phenomena. High-speed photography had been expanded with the development of the Laser-Illuminated Image Converter Camera (a very fast high-resolution 8-frame camera) and a 20-beam multiplexed Fabry-Perot velocimeter (Figure 5) had been developed to replace the original two-beam velocimetry recorder installed in Bunker 801 . With the 
change in concept from hardening diagnostic space to containing experiments, it would become relatively easy to expand diagnostic space which no longer needed to be in blast-hardened structures. As a consequence, the Contained Firing Facility was defined in terms of both containment and expanded diagnostic capability, and construction was begun in 1999. The new facility was completed in 2001 , and the first experiments were conducted this year.

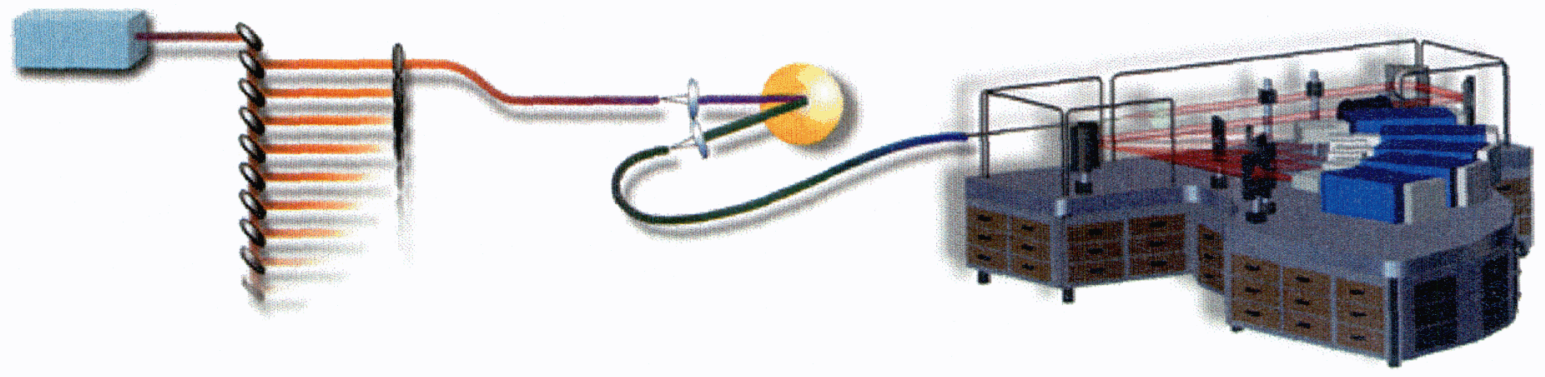

Figure 5. One of four, five-camera tables used to record doppler shifted velocimetry beams multiplexed through a single interferometer cell

\section{THE CONTAINED FIRING FACILITY}

The essential criteria for the CFF design were:

- Contain experiments with up to $60 \mathrm{~kg}$ of cased high explosive

- Design for a long chamber life ( $\$ 30$ years)

- Capture virtually all of the shot debris, including aerosolized depleted uranium and beryllium when present in the shot assembly, and any other hazardous materials

- Accommodate the broad range of complex experiments that had been historically conducted at Site 300

- Incorporate existing FXR and camera room

- Add space for the IC camera, manybeam velocimeter, and for future diagnostics

A near-zero discharge criterion necessitated elaborate air handling and water washdown systems, for which there was no good precedent. The new building has three major elements the firing chamber; a large gray area for experiment set up, and; a new diagnostic area with a local control room (Figure 6).

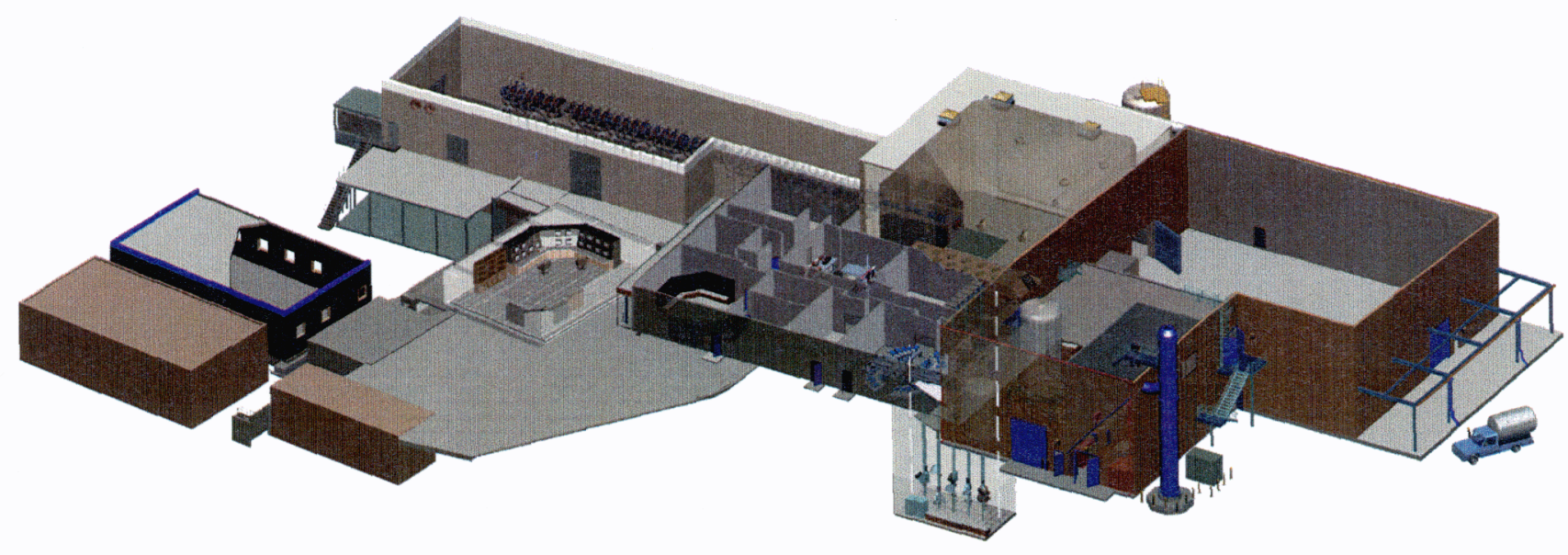

Figure 6. The new Contained Firing Facility 
The containment chamber measures 16 - by 18 -meters in floor area by 10 -meters in height, and is lined on the inside with 50-mm-thick steel sacrificial surface for protection against explosive-generated shrapnel (Figure 7)

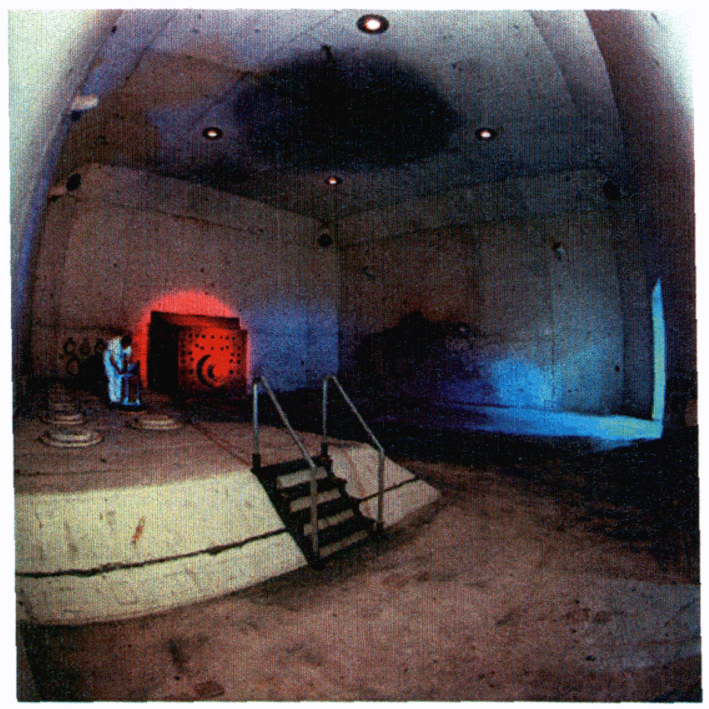

Figure 7: View of FXR bullnose inside the CFF containment chamber

The walls, floor and ceiling are constructed of heavily reinforced concrete with a minimum thickness of 1.5 meters. Access is principally by a 3.0 - by 3.8 -meters equipment door, with an ample number of ports ( $>60$ total penetrations total) provided for diagnostics. Chamber ventilation provides up to 20 air changes per hour, and passes through a purge scrubber and high efficiency particulate air filter before being exhausted to the atmosphere. A high-pressure water washdown sweeps over the entire chamber surface to clean the chamber. Particulates are collected in the form of a sludge, and the water is filtered for reuse. When the water is no longer usable, it can either be evaporated locally or sent to the Laboratory main site for disposal.

Immediately outside the equipment door is a large gray area that is used to stage experiments, house equipment needed for use in the chamber, and to serve as a buffer to the outside world where minor contamination from the movement of equipment into and out of the shot chamber can be accepted. The ventilation system for the gray area is separate from the chamber, and from the clean diagnostics area, and is controlled under normal operations at a negative pressure relative to the clean diagnostics area, and at a positive pressure relative to the chamber such that movement is from clean to more contaminated areas.

The diagnostics area is separated from the chamber by a second wall such that a leak from the chamber into the interstitial space (the chase) will not result in contamination of the clean diagnostic area apart from leakage through a second barrier. This was designed to provided adequate protection so that personnel could be present in the diagnostic rooms during an experiment. The diagnostic area is separated into multiple rooms, each with access to the shot chamber. One of the rooms will house lasers used for interferometry and for experiment illumination. Another will house the four 5-beam velocimetry tables. A local control room is included for convenience in diagnostic set up, though control during a test is done from the main control room. Other equipment currently available in the diagnostic area includes $\mathrm{xx}$ channels of digitizers for recording of contact pin, and other electrical diagnostics.

The CFF chamber was qualified with up to $75 \mathrm{~kg}$ of high explosive. Initial experience indicated some leakage past the chamber doors and ports. As a consequence, modifications were made to the door seals, and to the port flanges, which were very successful in reducing the leakage to very low levels. One experiment has been conducted with depleted uranium so far, and an experiment using beryllium is imminent.

After explosives experiments are conducted in the chamber, extensive sampling is done inside the chamber and in adjacent building spaces where leakage might occur. Real-time sampling detects the presence of $\mathrm{CO}$, a primary product 
of combustion. Other materials are measured in surface swipes and air samples taken both inside and outside of the chamber. Personnel wear protective equipment when entering the chamber and until it is safe to do otherwise.

\section{FXR UPGRADE}

Since its inception, FXR had been very successful in producing high-quality radiographs from explosive experiments. Experience with the machine increased understanding of linear induction technology, which has been of direct benefit in the development of new induction accelerators. It has also revealed areas where FXR improvements could be made to increase dose and decrease the focussed spot size, which largely determines radiographic image resolution. Four machine attributes in particular were shown to be performance limiting:

- High injector emittance (limited on FXR by a low injection energy and scatter from the wire anode grid)

- Inadequate accelerator cell voltage flatness (producing beam corkscrew motion)

- Poor accelerator magnetic alignment (aggrivating beam corkscrew motion)

- Strong RF excitations in induction cell cavities (producing a beam breakup instability)

As a consequence, an FXR Upgrade project ${ }^{2}$ was initiated a decade ago to address each of the above limitations by modifying the machine in increments while continuing to use the machine for explosives experiments. The upgrade consisted of four major elements.

\section{1) Improved focus coils with additional steering coils}

The original FXR focus coils were fabricated using 0.340 " square hollow copper conductor and were crudely wound on wooden mandrels and potted in epoxy. The result was a coil whose mechanical and magnetic axes were not aligned, nor at that time, easily determined with high accuracy. The coils fit over the $15-\mathrm{cm} f \mathrm{fl}$ beam pipe and, upon installation, were shimmed to be coaxial with the cell centerline, with resulting measured alignment accuracy ranging from 10- to 30milliradian tilts and up to 5-mm displacements from the accelerator axis. In addition, the magnetic centerline of a coil was not straight but 'wandered' due to the variations in the pitch of the windings. Tuning was made difficult because of a transverse field set up by the coils misalignment which tended to steer the electron beam away from the axis.

The design of the replacement focus coils represent a substantial improvement over the original design and is discussed Zentler ${ }^{3}$. The cross-section of a focus coil and its location in the accelerator cell is shown in Figure 8.

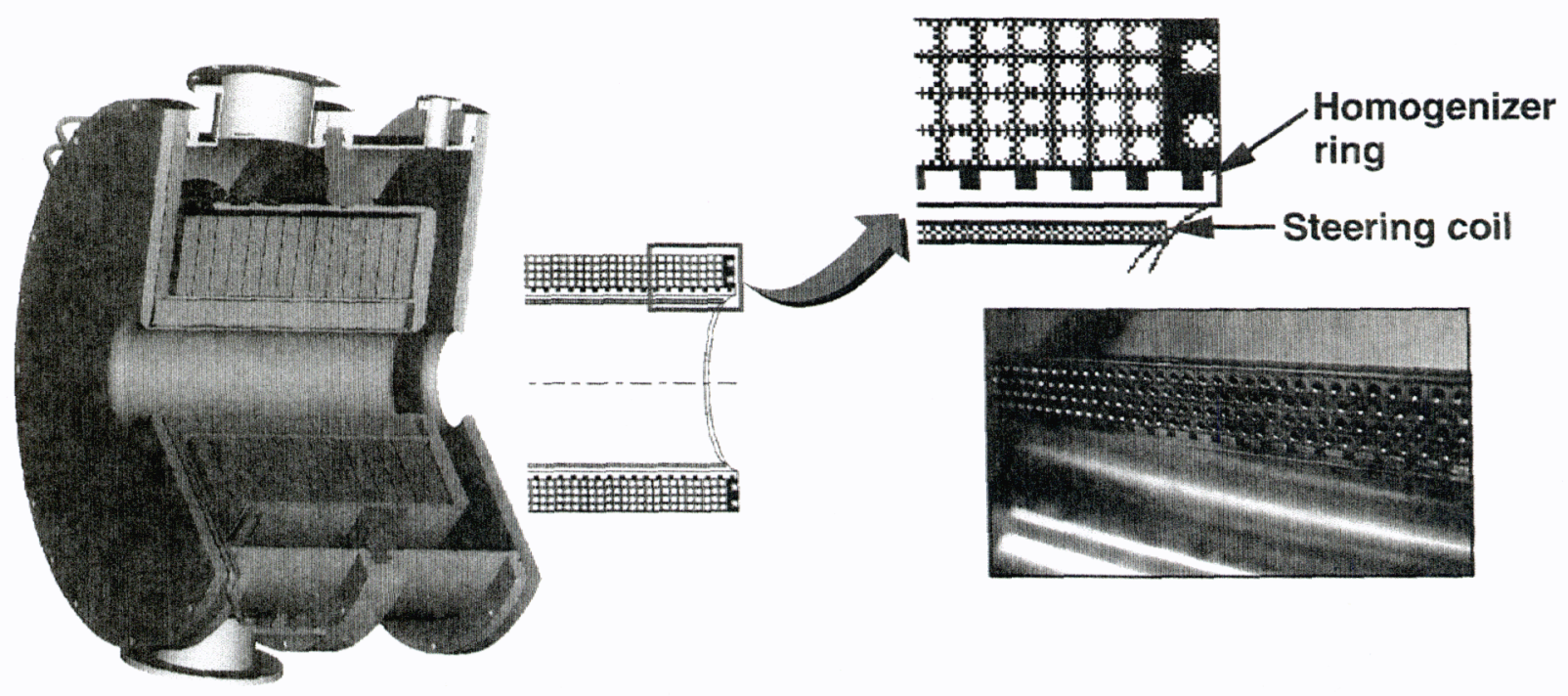

Figure 8: Cross-section of an FXR focus coil and its location in an accelerator cell. 
The new solenoids are bifilar wound instead of the original double two-layer design (one coil wound inside the other). The advantages of a bifilar design are: minimization of on-axis dipole-field errors by the symmetry of the design and reduction of winding pitch variations; and by increased magnetic field strength produced by higher current densities that result from shorter cooling water paths. The coils use 0.289 " square hollow copper conductor and generate magnetic fields of 5.67 Gauss/ampere and a maximum field of 2500 Gauss, as compared to 4 Gauss/ampere and 2000 Gauss maximum for the original coils.

Each solenoid was wound on a machined aluminum mandrel to achieve accurate winding and accurate placement of the solenoids in the accelerator cavities. Grooves, machined in the outside surface of the aluminum mandrel, were wrapped with transformer steel ribbon and serve as accurately placed homogenizer rings to short out any remaining transverse magnetic fields.

Printed circuit steering coils were installed in every solenoid to further reduce the magnetic misalignment and provide for active steering of the electron beam, if needed. These coils can generate a maximum steering field of 733 Gauss-cm with an energizing current of 5.0 amperes, with typical operation being less than 0.25 amperes.

With the new coils, a maximum of 0.1 - to 2-milliradian tilt and displacements of 0.01 - to 0.2 -mm were measured throughout the accelerator beam line. This represents an improvement in the transverse magnetic field errors of a factor of 10 to 20 (Figure 9). The active steering, using the printed circuit steering coils further reduced the amplitude of the beam corkscrew motion.

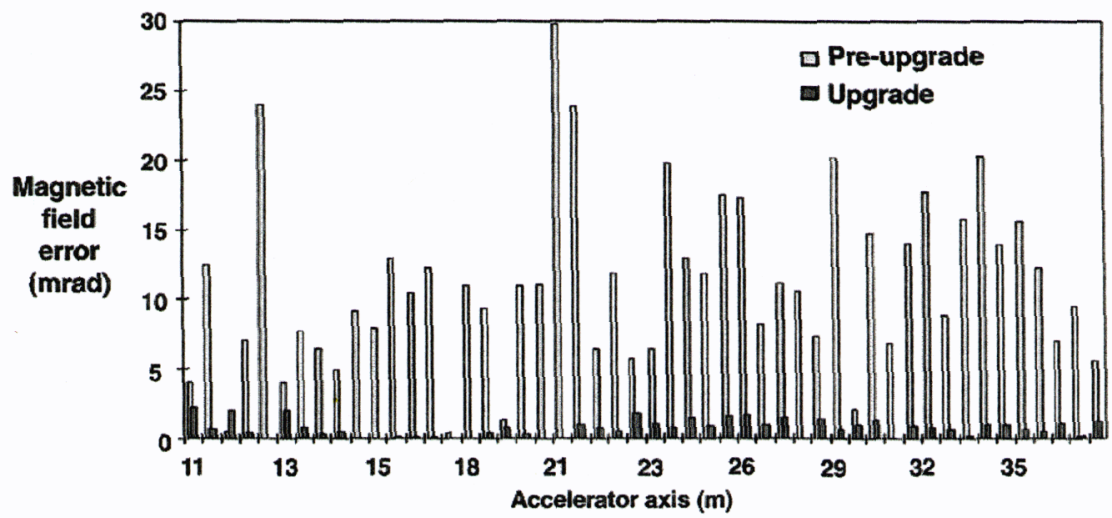

Figure 9. A comparison of magnetic field misalignment prior to and after the installation of the new focus coils. All measurements were made in situ.

\section{2) Redesign of the electron injector}

The FXR electron injector was upgraded to generate a higher current, higher energy and higher quality electron beam. The original injector ${ }^{4}$ consisted of six, near-standard accelerator cells. A cathode stalk threaded four of the cells with an anode stalk threading the remaining two. All six injector cells operated at $200 \mathrm{kV}$, producing a total voltage across the diode of 1.2 MV. The diode used a velvet field emission cathode and a grided anode, and produced a 2.2 kiloampere electron beam.

The upgraded injector was designed to operate using ten accelerator cells with each cell energized to $250 \mathrm{kV}$ for an overall voltage of $2.5 \mathrm{MV}$ and an electron beam current of 3.0 kiloampere (Fgure 10). The injector voltage and current waveforms are shown in Figures $11 \mathrm{a}, \mathrm{b}$ and an enlarged view of the diode and beam envelope through the transition region in Figure 12. This effort represented a substantial modification to the existing injector and involved a redesign of the diode, the anode and cathode stalks, and the injector-to-accelerator transition region. An additional nine focus coils were required for the injector, representing five separate solenoid designs, each based on the accelerator coil design, and incorporating homogenizer rings and steering coils. The increased beam energy and the removal of the anode mesh were designed to substantially improved emittance (producing higher beam brightness). A beam of lower emittance should translate to a smaller spot size on target. The new injector, like the original, uses a velvet field-emission cathode. 


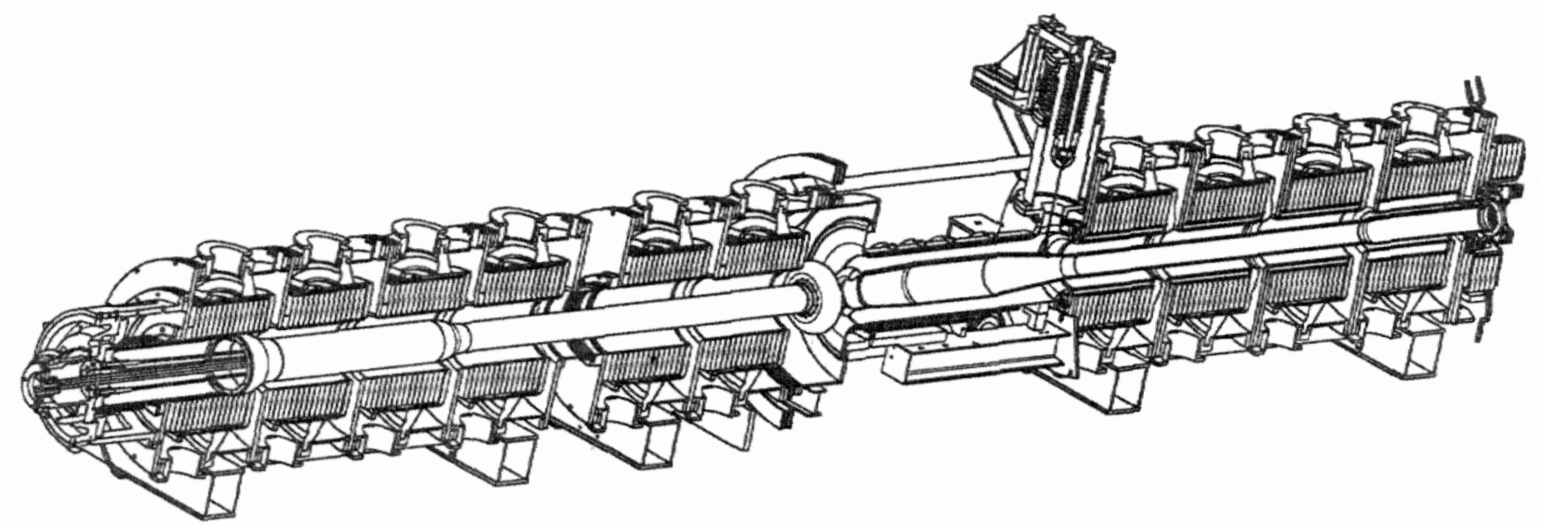

Figure 10: The FXR 2.5 MV, $3 \mathrm{kA}$ injector consists of 10 slightly modified accelerator cells.

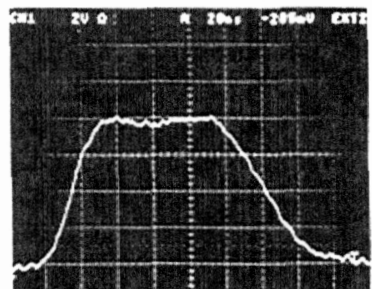

Fig. 11a: Injector Voltage Wave form. (20 ns/div).

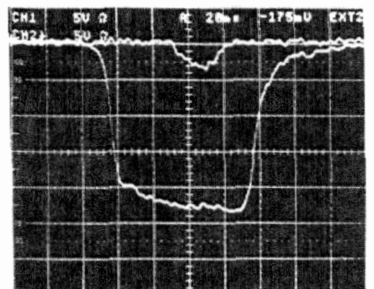

Fig. 11b: Injector Current Wave form. (20 ns/div.)

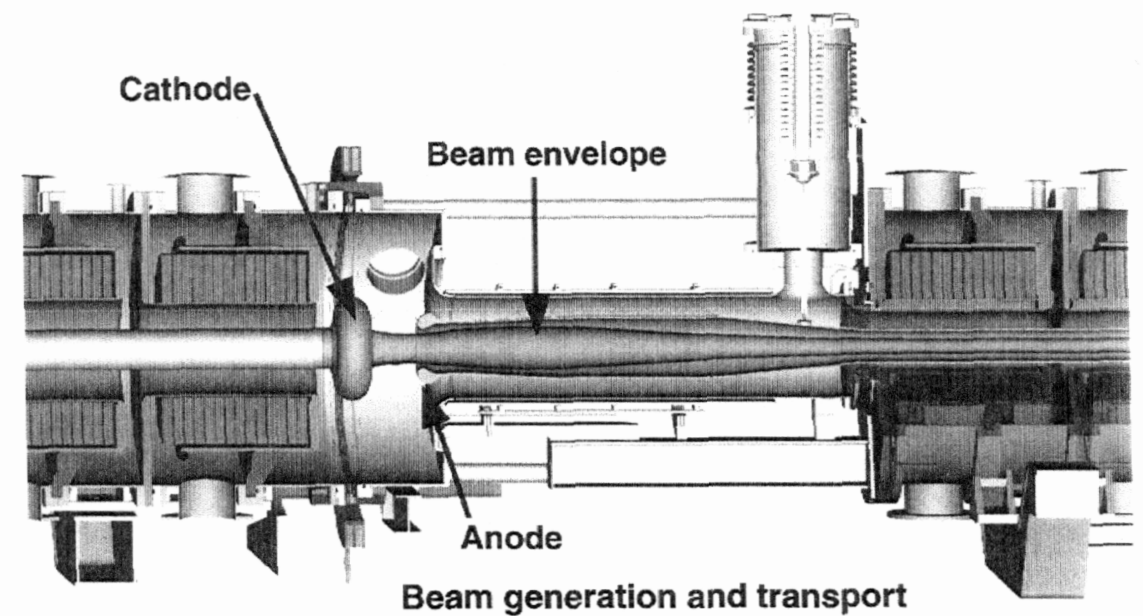

Figure 12: Enlarged view of the injector diode and electron beam envelope.

\section{3) Reducing the EM coupling between the electron beam and resonant electromagnetic modes of the accelerator cell}

The Beam Breakup Instability, or BBU, makes a contribution to the overall electron beam centroid motion and final beam spot size on the target. BBU is caused by the interaction of the electron beam with an accelerator cell s natural electromagnetic resonances. An off-axis beam couples to a non axi-symmetric RF cavity mode, which imparts a transverse force to the electron beam, kicking it further off axis. Theoretical models, computer simulations and experimental results all identify this to be a much more significant problem as the transported electron-beam current is increased from 2 to 3 kiloampere. Computer modeling ${ }^{5}$ of the RF response of an accelerator cavity using the AMOS FDTD simulation code along with experiments conducted on an FXR accelerator cell identified modifications that could significantly reduce the strong RF resonance at $820 \mathrm{MHz}$. The changes included adding a thin-walled RF reflector at the outer edge of the accelerator gap and placing RF absorbing ferrite toroids in the cavity feed and load lines. 


\section{4) Electron beam diagnostics}

As a part of the upgrade, restive-wall-type beam bugs, described by Struve ${ }^{6}$ were placed at 16 locations along the beam line. They provide time resolved beam current and centroid location. Beam-bug signals are recorded on each shot on 200 $\mathrm{MHz}$ digitizers. For beam tuning, the beam-bug signals are used with the 'Tuning V' algorithm, developed by Chen, ${ }^{7}$ to optimize the machine tune. Typical results are discussed in the paper by Ong. ${ }^{8}$ The 'Tuning V' involves adjusting each steering coil, to minimize the beam centroid motion, starting at the beginning of the accelerator and working through to the end. This procedure has proven to be very effective in minimizing the beam corkscrew motion.

\section{FXR DOUBLE PULSE UPGRADE}

The active nature of the gamma-ray camera opened the possibility of multiframe recording. At the same time, the high sensitivity of the camera suggested trading off dose for multipulsing. This led to the FXR Double Pulse Project, with the goal of producing from FXR two pulses of 60 Rad@1m separated by 1-5 s. This was to be accomplished by sequentially energizing alternate cells, or cell blocks in the injector and accelerator, using half of the full machine energy for each of the two pulses. The major components of this project were:

- The development of a two-frame gamma-ray camera

- Installation a second magnetic triggering system and rewiring of FXR for alternate cell, or cell block triggering

- Improving of cell voltage regulation to $-1 \%$, (which would also improve single pulse operation)

The Blumlein triggering scheme for double pulse operation is shown in Figure 13. The final modification made to the machine in the upgrade sequence was the addition of impedance-altering components to the Blumleins to achieve the $-1 \%$ cell-voltage waveform specification. Tests conducted on the Advanced Test Accelerator. had indicated that the velvet field-emission cathode used in single-pulse mode could also be used for double pulsing. Hydrodynamic calculations showed that the single-pulse solid tantalum x-ray converter target would stay sufficiently confined for the pulse separation period. An x-ray spot size of $<5.0 \mathrm{~mm}$ (MTF) was expected for each of the two pulses.

\section{Spak gap switches}

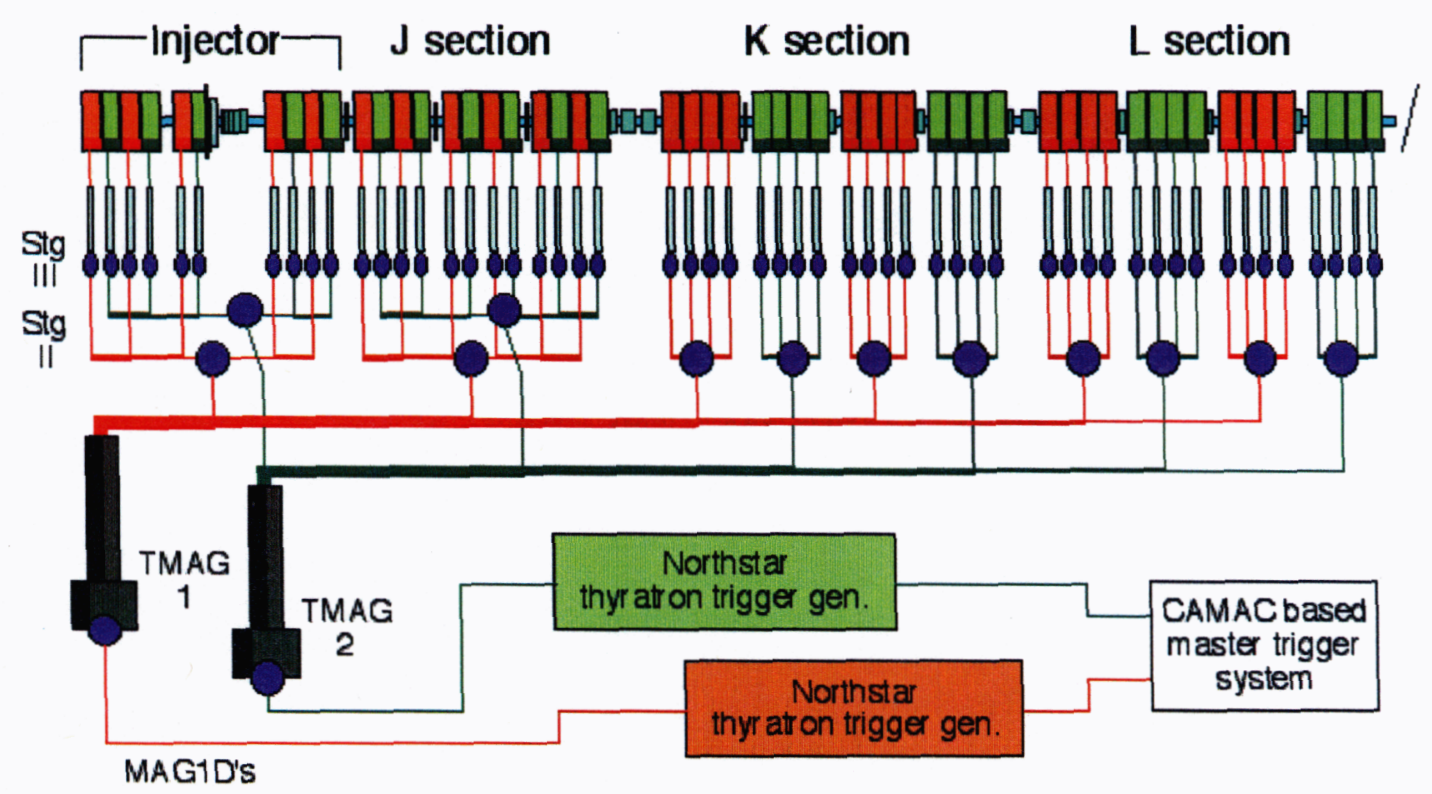

Figure 13: FXR Double Pulsing Scheme

The double pulse gamma-ray camera (see papers by C. Lai in this conference) was designed by coupling a BGO crystal array to a custom image converter tube. The output of the tube is directly coupled to two CCD arrays. The potential 
supplied to the deflection plates positions the image over the first $\mathrm{CCD}$, and then between FXR pulses, moves the positioning of the second image to the location of the second CCD.

\section{FXR UPGRADE RESULTS AND ONGOING IMPROVEMENTS}

The final upgrade modifications to FXR occurred during the construction of CFF, which was completed at the end of July, 2001. The period since then has been dominated by activities involving the commissioning of CFF, including a step-by-step process of gaining experience in handling hazardous material in a containment chamber. As a consequence, there has been limited testing of FXR. Nevertheless, many performance parameters have been measured, and the need for additional improvements is indicated.

The FXR Upgrade Project has significantly enhanced the radiographic capabilities of LLNL's hydrotest facility (see Table 1). As indicated by the relevant measure at the bottom of Table 1, the dose through the collimator used for most experiments has increased by a factor of 2.5 .

Table 1: FXR Operational Characteristics

\begin{tabular}{|lcl|}
\hline & $\frac{\text { Pre-Upgrade }}{1.2 \mathrm{MeV}}$ & $\frac{\text { Post-Upgrade }}{2.5 \mathrm{MeV}}$ \\
Injector energy & $16 \mathrm{MeV}$ & $17 \mathrm{MeV}$ \\
Final beam energy & $2.2 \mathrm{kA}$ & $3.0 \mathrm{kA}$ \\
Beam current & $300 \mathrm{Rad}$ & $450 \mathrm{Rad}$ \\
X-ray dose (@1 meter) & $3.5 \mathrm{~mm}$ & $3.5 \mathrm{~mm}$ \\
Spot size (MTF) & $50 \mathrm{Rad}$ & $125 \mathrm{Rad}$ \\
X-ray dose (@1 meter) through & & \\
0.8 -mm collimator & & $8.0 \mathrm{MeV}$ \\
Double pulse beam energy & $2.5 \mathrm{kA}$ \\
Double pusle beam current & $60 \mathrm{Rad}$ \\
Double pulse dose per pulse @ 1 meter & $<5 \mathrm{~mm}$ \\
Double pulse spot size (MTF) & & \\
\hline
\end{tabular}

However, the spot size has not improved as expected, though it does have a central peak (Figure 14) that has contributed to the collimated result. 

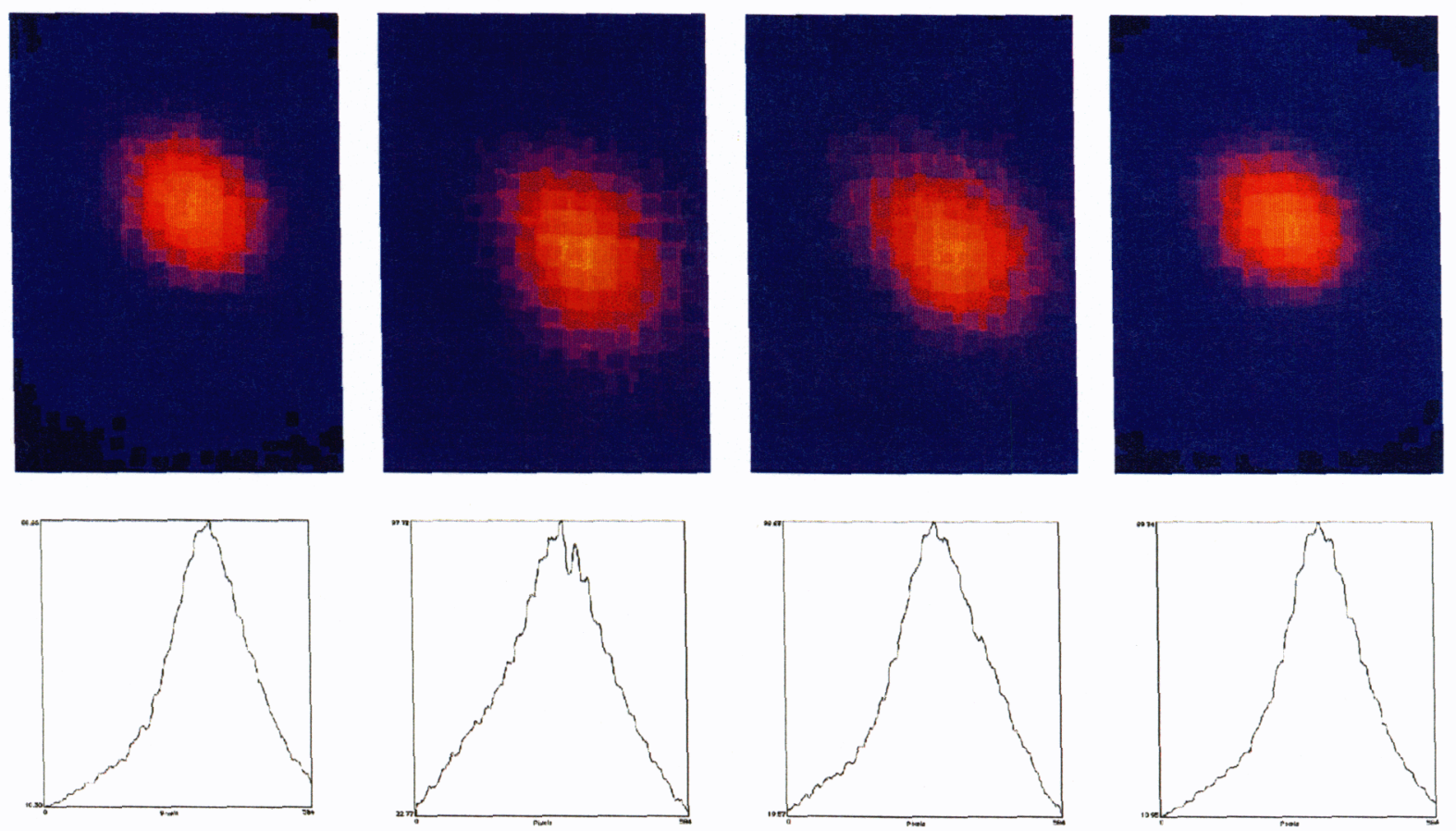

Figure 14: FXR pulse in 10 ns slices, with lineout traces shown below. [Note: that frame-to-frame images are not spatially aligned.]

Given the substantial improvement in the beam alignment, the reduction in BBU, the improved cell voltage regulation, and the expected improvement in the injector emittance, the absence of substantial improvement in the spot size was surprising. Subsequent measurements have indicated two dominating causes. First, the injector emittance did not improve as expected. The emittance measured in the first accelerator cell block is xxxxx. EGUN code modeling has substantially reproduced the emittance measured, and will be used to determine the further modifications necessary to achieve the potential of the higher voltage and grid-free design. Second, the improved cell voltage regulation was produced under static conditions (without an electron beam present). Accelerator cell voltage measurements have demonstrated that the presence of the beam pulse induces a current in the feed lines used to energize the cell, where a reflection occurs that perturbs the voltage waveform that the cell sees. The effect of the reflection has been reproduced in circuit modeling. A test stand is being assembled to further measure this effect and to determine how it can be mitigated. When modifications to these two elements are completed, substantially improved single and double pulse performance is expected.

In addition, research is being done on ETA-II to design a multipulsable target for the DARHT-II accelerator. ${ }^{9}$ This work has shown clearly that a high-current tightly-focussed beam will heat a Bremsstrahlung target, causing the liberation of gasses adsorbed onto the surface. Liberated gasses will be ionized by the beam and generate a counterflowing ion current that is accelerated by the beam potential. The effect of the ion current is to move the beam focal point upstream, leaving an expanded beam to strike the target (Figure 15). 


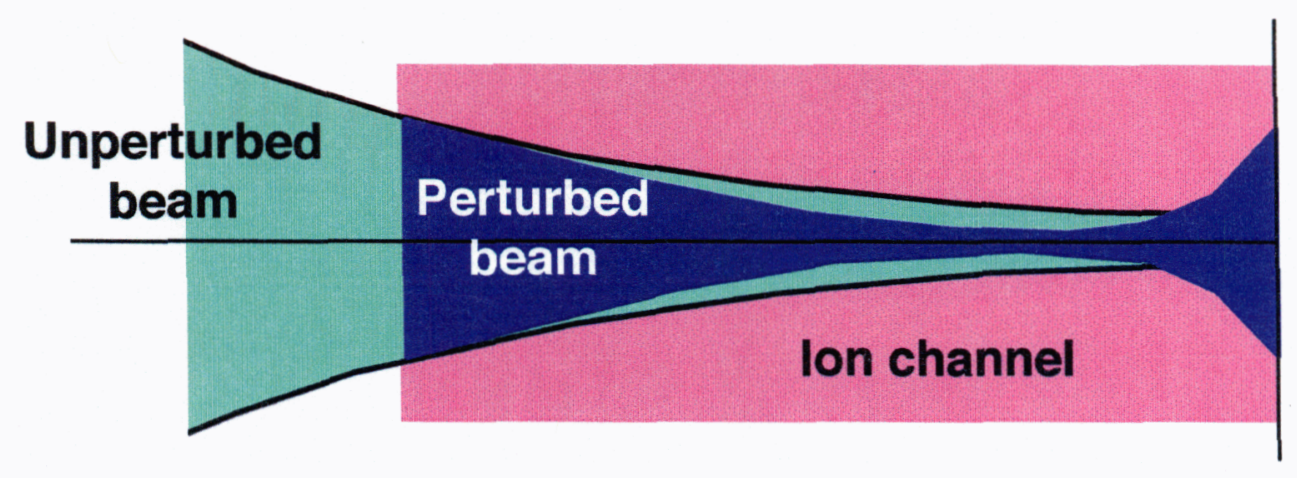

\section{Target}

Figure 15: Beam pinching caused by ion feedback.

The initial solution to this problem will be to use a ion-shorting foil just upstream of the target (Figure 16) where the larger beam radius causes much less gas desorption. The effectiveness of the foils has been demonstrated on ETA-II.

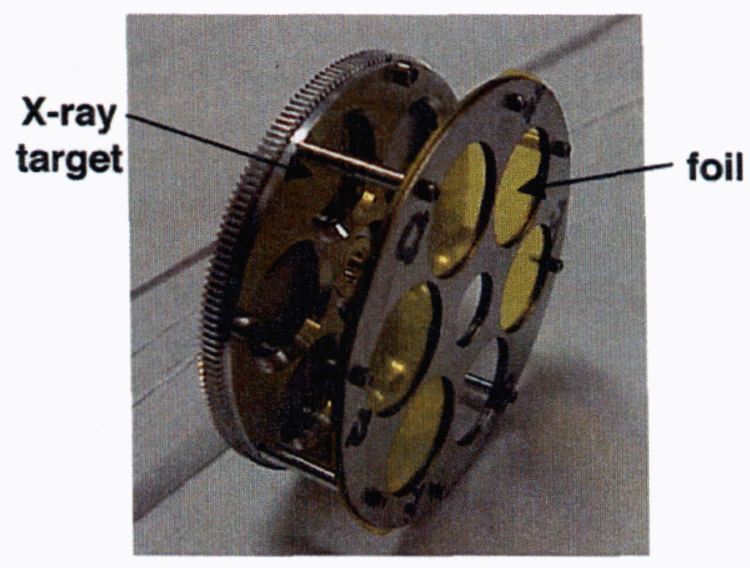

Figure 16: Bremsstrahlung targets with ion feedback shorting foils

In addition, the beam energy deposited in a target can cause hydrodynamic disassembly of the target material. For a single-pulsed machine, this is not a problem, except for the need to protect the accelerator from the molten target metal. However, for multipulsing, each pulse must either see new material (as from a possible future dynamic target), or the target must be designed to impede disassembly. Targets being developed for DARHT-II use a low-density tantalum foam or multiple tantalum layer stack in a tamping cylinder of solid material. This has been shown in both hydrodynamic calculations and in experiments to provide effective target confinement (Figure 17). While neither ion feedback nor target expansion is currently limiting for FXR in double pulsing mode, the targets being developed for DARHT-II would be essential to FXR if spot-size improvements can be achieved in the future. 


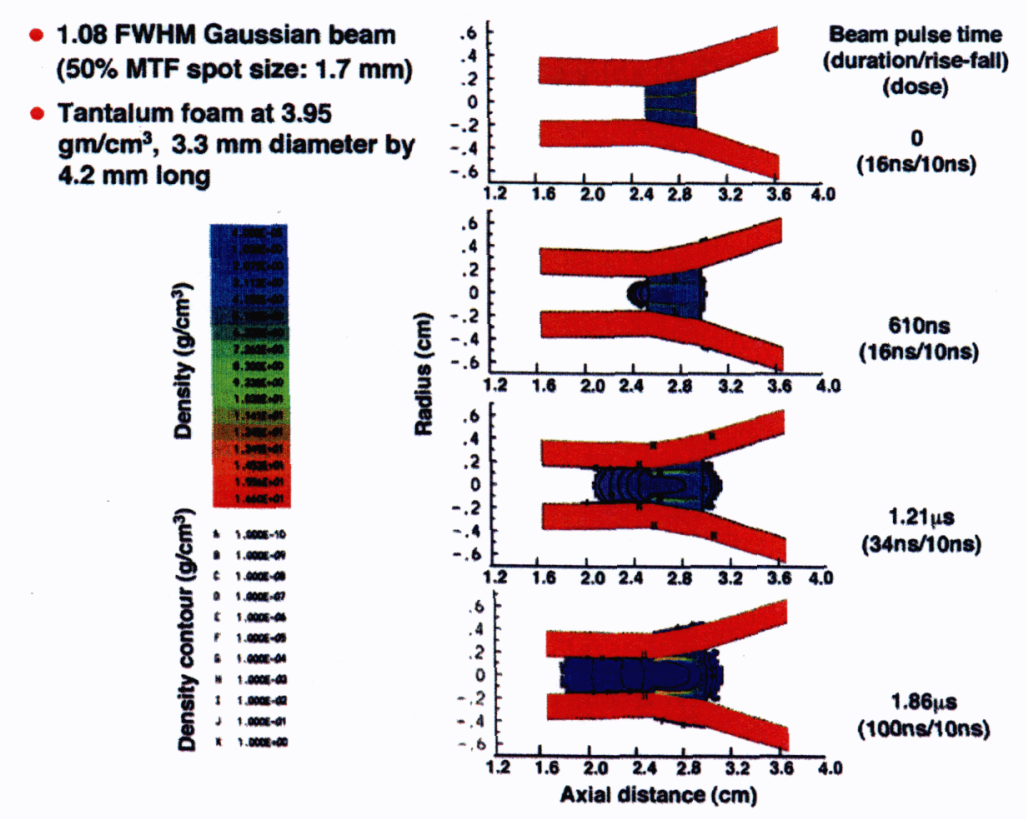

Figure 17: Tamped, tantalum foam target calculations

\footnotetext{
${ }^{1}$ Design of a $20 \mathrm{MeV}, 4 \mathrm{kA}$ Linear Induction Accelerator, B. Kulke, et al., 1980 IEEE Conference on Plasma Science, May 1980

${ }^{2}$ FXR Beam Upgrade, Site 300 Facilities Revitalization Project, R. Scarpetti, D. Goosman, November, 1994, LLNL report

${ }^{3}$ Improved Focus Solenoid Design for Linear Induction Accelerators, J. M. Zentler, R. D. Van Maren, 16th International LINAC Conference, Ottawa, Ontario, Canada, August 1992

${ }^{4}$ Beam Optics in the FXR 1.5 MeV, 4 kA Injector, R. D. Scarpetti, R. W. Kuenning, and K. C. Wong, Particle Accelerator Conference, Washington DC, March 1981

${ }^{5}$ EM Modeling of the FXR Accelerator Cavity, Scott Nelson, internal report UCRL -MI-120539, 1993

${ }^{6}$ Electrical Measurement Techniques for Pulsed High Current Electron Beams, K. W. Struve, Measurements of Electrical Quantities in Pulsed Power Systems-II NBS, MD, March 1986

${ }^{7}$ Beam Control in the ETA-II Linear Induction Accelerator, Y-J. Chen, 16th International LINAC Conference, Ottawa, Ontario, Canada, August 1992

${ }^{8}$ LLNL Flash X-Ray Radiography Machine Double Pulse Diagnostics, M. Ong, C. Avalle, R. Richardson, and J. Zentler, $11^{\text {th }}$ IEEE International Pulse Power Conference, June, 1997

${ }^{9}$ Downstream System for the Second Axis of the DARHT Facility, Yu-Jiuan Chen, et. Al., XXI International LINAC Conference, Gyeongju, South Korea, August, 2002.
} 